ARTIGO

\title{
O USO ESTRATÉGICO DA IDENTIDADE, IMAGEM E REPUTAÇÃO \\ ORGANIZACIONAL: CONTRIBUIÇÃO DA COMUNICAÇÃO SOBRE AS POSSIBILIDADES E DESAFIOS DESSA PRÁTICA ${ }^{1}$
}

\author{
Dôuglas Aparecido Ferreira²
}

\begin{abstract}
RESUMO
Este ensaio teórico se propõe a fazer uma reflexão sobre a utilização estratégia da identidade, imagem e reputação organizacional na gestão das empresas. Para tanto, serão resgatados autores com perspectivas diversas sobre a temática, às vezes dialogando com os estudos funcionalistas e outras vezes com uma abordagem mais complexa e relacional. O estudo leva a inferir sobre a relevância de se descolocar de um olhar prescritivo da comunicação para uma visada mais dinâmica que reconheça o constante processo de (re)construção das organizações a partir das interações que estabelecem com os outros atores sociais.
\end{abstract}

Palavras-chave: Identidade. Imagem. Reputação. Comunicação no Contexto das Organizações.

\section{INTRODUÇÃO}

A identidade, a imagem e a reputação, ao longo dos últimos anos, vem se tornando temas relevantes entre os estudos da comunicação organizacional, bem como os do campo da administração. A emergência desses estudos é reflexo do constante uso estratégico dessa tríade pelos gestores contemporâneos, principalmente por aqueles interessados em aumentar o valor simbólico de uma marca, hoje um dos principais ativos intangíveis para uma organização.

Além disso, o contexto econômico atual marcado pela sociedade do consumo e pela velocidade das mudanças socioculturais compõe um plano de fundo propício para que esses assuntos estejam em evidência. Afinal, a cada dia mais, as organizações buscam se posicionar

\footnotetext{
1 Como citar este artigo: FERREIRA, Dôuglas Aparecido. O uso estratégico da identidade, imagem e reputação organizacional: contribuição da comunicação sobre as possibilidades e desafios dessa prática. ForScience: revista científica do IFMG, Formiga, v. 6, n. 3, e00429, jul./dez. $2018 . \quad$ DOI: 10.29069/forscience.2018v6n3.e429.
}

\footnotetext{
${ }^{2}$ Autor para correspondência: Dôuglas Aparecido Ferreira, UFMG/UFMT, e-mail: douglasferreira@ufmt.br.
} 
frente a essas mudanças se utilizando de métodos para dar relevância ao que elas entendem por identidade, imagem e reputação (ALVESSON, 1990).

A intenção deste ensaio crítico-teórico é apresentar perspectivas sobre a possível relação entre a identidade, imagem e reputação organizacional e apresentar a contribuição dos recentes estudos da Comunicação sobre essa temática. Para tanto, inicialmente será feito o resgaste de abordagens que fazem uma ligação entre cultura e identidade organizacional. Em seguida, serão problematizados os imbricamentos dos conceitos de identidade, imagem e reputação e a frequente utilização desses pressupostos como manobras estratégicas em uma organização, como, por exemplo, na seleção de novos empregados. Cabe destacar que ao longo do texto será acrescentado ao debate o ponto de vista da comunicação - vista aqui como um processo relacional ${ }^{3}$ - quanto à complexidade do gerenciamento da identidade e da construção da imagem, reforçando a incapacidade das trocas interacionais em alcançar os determinismos buscados pelos gestores no campo simbólico e representacional.

É importante destacar que as abordagens resgatadas a seguir são apenas recortes menores de dois campos extremamente prolíficos - Administração e Comunicação. Portanto, seria muita pretensão chegar a uma conclusão sobre até onde e de que forma seus estudos avançaram para se entender como o uso estratégico da identidade, imagem e reputação e sua manifestação na gestão de marcas. Na verdade, a finalidade aqui é, através do diálogo entre os autores, rascunhar um cenário e pontuá-lo com uma discussão crítica, tencionando as abordagens e problematizando a questão proposta.

\section{CONTRIBUIÇÕES DOS ESTUDOS DA COMUNICAÇÃO PARA SE ENTENDER A DINÂMICA RELACIONAL ENTRE IDENTIDADE, IMAGEM E REPUTAÇÃO ORGANIZACIONAIS}

De forma sucinta, pode-se dizer que a prática da gestão de marcas se utiliza de alguns princípios da psicologia e da filosofia para discutir questões chaves: quem é a organização? Quais são seus principais atributos? Qual o seu propósito? Obviamente, não é uma tarefa fácil responder a essas perguntas. Gioia (1998) destaca isso ao afirmar que o conceito de identidade, que é tão apropriado para entender o que significa ser humano, também é central

\footnotetext{
${ }^{3}$ Paradigma cunhado pela pesquisadora Vera França, que entende a comunicação como um "processo de produção e compartilhamento de sentidos entre sujeitos interlocutores, processo sempre marcado pela situação de interação e pelo contexto sócio-histórico" (MAIA; FRANÇA, 2003, p. 188) 
para a conceituação do que ele define como uma das mais complexas e fascinantes criações humanas, as organizações.

Segundo Schultz (2005), duas correntes sobre identidade buscam respostas para a sua conceituação. Em uma delas, que pode ser chamada de primeira corrente ou corrente clássica, a identidade é normalmente tomada como a compreensão de uma organização coletiva com características presumivelmente centrais e relativamente permanentes, que distinguem uma organização de outra (GIOIA; 1985). Essa perspectiva se fundamenta em uma visão funcionalista da identidade ao considerá-la como resultado de uma escolha estratégica da alta gestão e que, por ser assim, deve ser projetada, de forma linear e vertical, através de ações de comunicação, para todos os grupos de interesse.

Há argumentos ainda mais incisivos em relação à identidade organizacional. Ligia Fascioni (2010) defende o conceito de DNA empresarial, isto é, uma estrutura composta por todos os atributos essenciais e acidentais de uma organização que a faz única e diferente de todas as outras e, assim como a estrutura genética humana, somente sofre mutações em casos extremos, como a fusão com outro DNA (empresa), por exemplo. A autora explica que uma vez constituída a empresa, é muito difícil mudar sua identidade, com exceção para quando se aplica técnicas sofisticadas que envolvem investimento de tempo e dinheiro. (FASCIONI, 2010).

Em contrapartida a este pensamento, Hatch e Schultz (2000) lembram que alguns autores como Giorgia e Thomas, Zygmunt Bauman e Stuart Hall discordam de que a identidade seja estática. Esse movimento pode ser conhecido como a segunda corrente dos estudos da identidade organizacional e traz à discussão a ideia de que a identidade se dá a partir das interações comunicacionais entre a organização e seus interlocutores. A autoras sustentam que "se o problema moderno na identidade era como construir uma identidade e mantê-la sólida e estável, o problema pós-moderno da identidade é principalmente o de evitar a fixação e manter as opções abertas.” (HATCH; SCHULTZ, 2000, p. 8).

Gioia (2000) parece concordar com os autores supracitados ao destacar que a identidade não é e nem pode ser algo permanente, mesmo que, aparentemente, mantenha a continuidade de seus atributos essenciais. O autor advoga que deve haver fluidez, caso contrário, a organização estagna nos inevitáveis ambientes de mudanças.

Uma possível linha de raciocínio para esclarecer ainda mais a discussão sobre a identidade organizacional pode estar no próprio cerne da questão, ou seja, naquilo que dá 
origem à identidade, mas que está tão intrínseco à organização que se torna mais complexo seu estudo: a cultura organizacional.

Hatch e Schultz (2000) lembram que a cultura organizacional contextualiza a identidade. De modo comparativo, é como se a cultura fosse algo inconsciente, inalcançável, sabe-se que ela existe, mas não se sabe por que se manifesta de um determinado jeito. Por sua vez, a identidade parece ser a parte mais racional da cultura, aquilo que os sujeitos podem perceber e conseguem expressar a existência. Desse modo, ela acaba sendo mais consciente e acessível do que a cultura.

Para Balmer e Riel (1997), a cultura organizacional nasce de um emaranhado de valores e crenças compartilhados entre o fundador da organização, os profissionais que nela atuam e a cultura externa que a cerca. Desse modo, se a cultura organizacional é algo sujeito à diversas interferências, talvez essa flexibilidade também seja refletida, mesmo que em partes, na identidade corporativa (BALMER; RIEL, 1997). Pode-se reforçar essa ideia ao se afirmar que "o que faz uma empresa são as pessoas que trabalham nela. São essas pessoas que constroem a sua cultura, a sua identidade organizacional." (FASCIONI, 2010, p. 54). Sendo assim, "a cultura pressupõe, sujeitos em relação/interação. São sujeitos que ao (re)tecerem a rede simbólica se relacionam/interagem suas alteridades e com elas disputam e constroem sentidos. (BALDISSERA, 2008, p. 163). Esses argumentos reforçam a dificuldade de se concordar com a ideia de que a identidade possa ser uma entidade fixa e acabada, uma vez que ela é resultado das complexas interações que constituem a cultura.

$\mathrm{Na}$ tentativa de se contextualizar as perspectivas apresentadas até aqui, será recortada a possibilidade da utilização da identidade na prática dos processos de seleção de novos empregados geralmente pautados na busca de perfis semelhantes aos atributos da organização. Alguns estudos alocados na primeira corrente defendem a perfeita comunhão de atributos entre novos empregados e a identidade organizacional.

Imagine uma pessoa extremamente ousada, trabalhando numa empresa essencialmente conservadora. É só uma questão de tempo para que ela peça para sair, ou seja mandada embora, sem que nenhuma das partes esteja errada (errado foi o processo de seleção!). (FASCIONI, 2010, p. 55).

Fascioni (2010) ainda faz uma analogia acerca do conceito de imagem. Para a autora, a imagem parte de uma tela branca que as pessoas trazem em suas mentes em relação a uma determinada organização com a qual ainda não se relacionaram. A partir disso, a imagem é montada à medida que a tela vai sendo preenchida, como se fosse um quebra-cabeça, com 
peças que a própria organização fornece. Daí, segundo a autora, se a organização não se conhece, ela não oferecerá à sociedade, as peças corretas para o preenchimento desta tela branca. Para Fascioni (2010), quando isso acontece, a imagem "gerada” está distorcida.

É só pensar: o nome da empresa é uma peça. Um outdoor que você vê na rua, outra peça [...]. No decorrer da experiência, você vai formando uma opinião, um quadro ou, em outras palavras, uma imagem da tal empresa. (FASCIONI, 2010, p. 57).

Percebe-se, na analogia feita pela autora, uma tendência à perspectiva positivista da construção da imagem. Fascioni considera apenas o fenômeno de transmissão da mensagem e ignora a complexidade do processo e as interferências do contexto, das estratégias e da produção de sentidos. Ou seja, há outros elementos do processo comunicativo além da emissão e recepção que foram desconsiderados em sua proposta.

Fascioni (2010) ainda defende que essas "peças" bem encaixadas e distribuídas de maneira fidedigna à identidade, não necessariamente resultam em um total esclarecimento da sociedade de quem a organização é, mas podem aumentar a chance de uma leitura mais coesa por parte dos sujeitos. A divulgação da identidade é uma estratégia comunicacional geralmente utilizada para reforçar na sociedade as qualidades de uma organização. $\mathrm{O}$ resultado dessa interação é conhecido por imagem, isto é, uma construção simbólica que se forma na mente daqueles que tiveram algum contato com a organização. "Várias pessoas, submetidas à mesma mensagem, constroem em suas mentes imagens completamente distintas. Cabe ao interessado em transmitir a mensagem, o cuidado para que ela seja bem entendida pelo receptor". (FASCIONI, 2010, p. 55). A perspectiva da autora citada reduz a comunicação a um processo simplista, em que a instância de produção das mensagens é a única responsável pelo "sucesso" do fenômeno. Quanto a isso, Ângelo e Vance (2007) acrescentam que a imagem da organização é afetada pela publicidade realizada, por suas ações junto à comunidade, pela propaganda na mídia, ou seja, pelas informações recebidas pelos indivíduos sobre ela. Nestes conceitos apresentados de imagem, nota-se uma perspectiva funcionalista, focada apenas nas intenções das organizações, como se o processo comunicativo fosse amplamente controlado por elas.

Outro exemplo desse determinismo, pode ser encontrado nas ideias de Pruzan (2001), ao dizer que os "empregados brilhantes, dinâmicos, independentes e empregados criativos querem sentir que há uma harmonia razoável entre os valores empresariais e seus valores pessoais." (PRUZAN, 2001, p. 54). Aparentemente, Fascioni (2010), Ângelo e Vance (2007) e Pruzan (2001) defendem a importância de se construir um alinhamento entre os valores que uma 
empresa carrega em sua identidade e os valores que os empregados trazem em seu caráter pessoal, como se a identidade organizacional fosse uma entidade sólida o bastante para ser também fidedignamente encontrada nas pessoas. A partir do viés comunicacional, a crítica que pode ser feita à visão desses autores é que ela desconsidera a construção de sentido dos "valores empresariais" pela instância da alteridade. Dito de outra forma, os valores empresariais e os valores pessoais são dimensões de significações com sentidos indefinidos.

Todavia, é importante entender que a relação entre as organizações e seus públicos não se dá de forma determinista e estaque, pelo contrário, ela é sempre um devir, uma construção e uma negociação. A ideia da comunhão dos valores e o perfeito alinhamento entre a organização e os seus empregados, por exemplo, podem indicar uma prática comum das organizações de tentar ditar certos comportamentos desejados no ambiente de trabalho. Contudo, quando se pensa a comunicação como um processo relacional, e que é através dela que os sujeitos constroem seus discursos, suas significações, apresentam suas intenções e suas estratégias, seria inviável imaginar que durante a seleção de empregados, os recrutadores conseguissem perceber um alinhamento entre a identidade organizacional e a identidade de um candidato à vaga de emprego, mesmo que para isso se utilize técnicas refinadas de psicologia para o entendimento da personalidade. Isso se deve ao fato de que, segundo Goffman (1995), os sujeitos estão o tempo todo assumindo papéis de representação de acordo com suas estratégias do cotidiano e sustentadas por aquilo que eles acreditam ser o que seus interlocutores esperam dele. Essa possibilidade demonstra a habilidade dos atores sociais de fazerem uma leitura crítica da situação e adequarem sua performance àquilo que lhe são exigidos, sem necessariamente corresponderem exatamente ao que são. Dito de outra forma, “[...] o indivíduo é um ator social, ele é, também e simultaneamente, o resultado em constante mutação, de ações e reações externas e internas a dinâmicas culturais e sociais." (FERIN, 2004, p. 62).

Não se pode esquecer que as organizações são ambientes onde a disputa de interesses e as relações de poder são características marcantes. Por ser assim, é preciso se ter cuidado para não diminuir a comunicação a uma atividade estritamente prescritiva, com resultados calculados e previsíveis. Afinal, em um ambiente como o das organizações, que vem sendo dominado cada vez mais pela ideia de gestão, existe a ilusão de que se possui a forma de bem conduzir as coisas, de maneira que as coisas atinjam seus objetivos. (PINTO, 2008).

Aqui está um ponto importante quando se aproximam práticas organizacionais funcionalistas e a perspectiva da comunicação por meio de seu paradigma relacional. Percebe- 
se uma preocupação dos gestores apenas na instância emissora, desprezando a situação em torno da interação e delegando às próprias organizações o resultado da construção da imagem em seus públicos. Esse posicionamento vai de encontro, a definição de imagem defendida pelos recentes estudos da comunicação no contexto organizacional no Brasil, que entendem esse mesmo fenômeno da relação identidade-imagem de forma mais complexa, como pode ser visto pela definição a seguir:

\begin{abstract}
Imagem-conceito é um constructo simbólico e sintetizante, de caráter judicativo/caracterizante e provisório, realizada pela alteridade (recepção) mediante permanentes tensões dialógicas, dialéticas e recursivas, intra e entre uma diversidade de elementos-força, tais como as informações e as percepções sobre a entidade (algo/alguém), o repertório individual/social, as competências, a cultura, o imaginário, o paradigma, a psique, a história e o contexto estruturado (BALDISSERA; KAUFMANN, 2013, p. 69)
\end{abstract}

$\mathrm{Na}$ fala dos autores nota-se um deslocamento da perspectiva da instância de produção para a instância de recepção, afinal é nela onde acontece a construção da imagem e, por ser assim, se torna inviável qualquer alinhamento ou controle entre a produção de sentidos que despreze a complexidade desse processo.

Baldissera lembra que a comunicação organizacional pode ser entendida em três dimensões: organização comunicada, comunicante e falada. Basicamente, a organização comunicada é a fala formal e autorizada da empresa, aquela planejada que visa um retorno bem definido. A organização comunicante é aquela que foge do grupo de pessoas que inicialmente a organização pretendia atingir e, por estar em circulação, estabelece relação com qualquer interlocutor. Por fim, a dimensão falada é a comunicação indireta, aquela que não acontece através da organização, ocorre fora dos âmbitos das relações diretas, em diversos contextos e podem se materializar nas casas dos empregados, no clube esportivo, nos jornais, nas universidades, etc. (BALDISSERA, 2010).

Portanto, a partir das discussões do autor, pode-se avançar na ideia de que a comunicação organizacional também é composta por aquilo que não é planejado o que convoca a percepção de uma série de possibilidades de produção de imagens que nem sempre partem da própria organização. E este é o paradoxo que as organizações enfrentam em uma busca do alinhamento de sua identidade e um reflexo muito próximo dela na imagem criada e sustentada pelos públicos.

Embora haja estudos mais contemporâneos sobre a comunicação no contexto das organizações, pautados no paradigma da complexidade (BALDISSERA, 2004), a grande maioria pauta-se no paradigma funcionalista, onde a ideia de sistema e subsisltema é tão harmoniosamente 
engrenada e administrada que considerar o imprevisto e o não-habitual é algo contrário à lógica do negócio. Na perspectiva da gestão é um contra-senso pensar em movimentos de oposição e de posicionamentos diferenciados, já que seus princípios pressupõem o controle e aperfeiçoamento dos processos para se obterem os resultados maximizadores. (PAULA; OLIVEIRA, 2012, p. 92)

O ponto de vista das autoras convida a pensar nos públicos que se relacionam com as organizações como sujeitos que refletem o desalinhamento natural dos sentidos e sua interdependência do contexto onde são construídos e disputados. Nestas situações, é comum a frustração das organizações que de modo geral acreditam em uma sobreposição dos sentidos que ela propõe para a sociedade.

Almeia e Nunes (2007) explicam que o uso estratégico da imagem ao longo do tempo causam o surgimento de outro fator relevante para as organizações, a reputação. Eles distinguem as imagens como momentâneas, mutáveis e adaptativas enquanto a reputação é relativamente estável.

A reputação vem ganhando relevância no contexto organizacional atual. Em momentos de crise econômica ou escândalos envolvendo organizações, o termo "reputação" é amplamente utilizado para garantir a integridade de um negócio. A reputação faz muita diferença quando alguém precisa confiar na empresa por algum motivo (FASCIONI, 2001). Todavia, se encararmos o mundo contemporâneo como um cenário de incertezas, conceitos até então considerados duradouros como as reputações estão sendo revistos. A sociedade contemporânea é uma sociedade fluida onde tudo tende a tornar-se volátil, flexível e em fluxo (LIMA, 2008).

Ainda se utilizando da seleção de empregados como exemplo pontual, pode-se presumir que de forma geral os candidatos fazem uma pesquisa em busca de informações relevantes das organizações em que desejam trabalhar. "Quando os estudantes escolhem seus empregos, eles geralmente consideram os mais atraentes aqueles oferecidos pelas empresas de melhor reputação no momento.” (FOMBRUN; RIEL, 2004, p. 3). A reputação de uma empresa se torna, a cada dia, um elemento significativo que interfere diretamente na gestão de pessoas. "É vital para as empresas serem capazes de atrair e manter os empregados bons, criativos, muitas vezes altamente qualificados e educados - e eles são extremamente sensíveis à reputação das empresas." (PRUZAN, 2001, p. 5).

Uma das ferramentas estratégicas que as organizações têm usado para atrair mais talentos para seu grupo de empregados é conhecido por Employer branding. Esta expressão é 
usada para denominar o conjunto de táticas de construção da reputação, com o objetivo de tornar as empresas mais atraentes para os empregados atuais ou em potencial.

Num relatório de fevereiro de 2001 patrocinado pelo gigante de serviços financeiros Charles Swab, executivos de 138 organizações-líderes responderam a uma pesquisa acerca de suas experiências e práticas de branding. Eles indicaram que os desafios para os empregadores incluíam não apenas convencer os empregados potenciais de que a organização era um bom lugar para trabalhar e efetivamente conseguir os melhores candidatos por meio de um processo de recrutamento e contratação, mas também retê-los e assegurar sua compreensão dos objetivos e da missão da organização. (FOMBRUN; RIEL, p. 11, 2004).

Os termos "convencimentos" e "assegurar a compreensão" se mostram como exemplos da tentativa das organizações de que seus atributos sejam rigorosamente encontrados nos futuros candidatos às vagas de empregos. Outro fator importante é a relevância que a interação pela internet ganhou neste novo cenário em que os candidatos ao emprego usam este veículo em busca de informações sobre a empresa. "Se uma página da internet é pouco informativa, confusa e desatualizada ou simplesmente uma réplica de um folheto, pode desmotivar os candidatos mais qualificados." (FOMBRUN; RIEL, 2004, p. 11). Esses novos tempos já despertaram um novo comportamento dos empresários, levando-os a atribuir uma importância maior à disseminação da identidade de suas empresas.

\footnotetext{
Os esforços de comunicação da empresa com seus principais grupos de interesse são um importante antecedente para criação de uma boa reputação. Assim, a área de comunicação desempenha um papel relevante através de suas mensagens corporativas, seja nas ações de relações públicas, nas campanhas de marketing para divulgação de seus produtos e serviços ou mesmo prestando contas aos principais grupos de relacionamento acerca de suas ações de responsabilidade social ou ambiental. (NUNES, 2007, p. 13).
}

Para os autores mencionados, a comunicação tem um papel significativo no processo entre a definição da identidade, a formação da imagem na cabeça dos indivíduos e a construção da reputação ao longo do tempo. Para eles, a comunicação organizacional representa o processo pelo qual os stakeholders percebem a identidade da empresa e através dela, a imagem e a reputação são construídas. E vão além, eles acreditam que por meio da comunicação é estabelecida uma relação controlada entre a identidade da organização e sua reputação, o que seria uma vantagem competitiva principalmente se os sujeitos associam uma inseparabilidade entre identidade, comunicação, imagem e reputação. (BALMER; GRAY apud ÂNGELO; VANCE, 2007). 
Todavia, encarar a comunicação como um processo unidirecional em que uma organização dita para a sociedade a sua identidade, e esta, de forma passiva, a aceita, é limitar o fenômeno. Quando se fala em reputação, deve-se entender que se trata de uma percepção complexa dos diversos grupos que se relacionam com a organização e, entre eles, estão diversos atores sociais com repertórios e experiências distintos. Por ser assim, o processo de gerir e mensurar a reputação, a partir de uma tentativa de imposição de significados, acaba se tornando uma falsa impressão de controle sobre o processo. Afinal "diante de todo este cenário, entendemos que a cultura, identidade, imagem e reputação de uma organização não pode apenas ser definida pela própria organização, mas é construída socialmente." (ALMEIDA; PAULA; BASTOS, 2012, p. 90). Essa construção acontece na alteridade, com base nas diversas fontes de informação e experiências que os públicos têm com os produtos e serviços, atendimento, investimentos realizados, atitudes e comportamentos da organização, em um processo infinito de significação e resignificação de sentidos.

É certo que a comunicação contribui significante para que os processos de interação aconteçam entre a organização e seus públicos. Mas, a problemática está no fato de esperar do processo comunicativo um resultado que se aproxime de um total alinhamento daquilo que uma organização entende por identidade e aquilo que os sujeitos constroem em suas mentes. Essa perspectiva reducionista não leva em consideração que os sujeitos também possuem suas intenções e estratégicas, geralmente menos evidentes do que as intenções e estratégias organizacionais devido a desproporção da visibilidade dessas últimas em relação aos primeiros.

Para um melhor esclarecimento do que foi discutido, há que se pensar que a comunicação, vista como um processo relacional entre interlocutores envolvidos em um determinado contexto, não pode ser encarada como uma ferramenta totalmente a serviço da gestão. Sendo assim, termos como "resultados" e "previsibilidade" não fazem sentido quando se tem a ideia de comunicação como processo social de produção de sentidos, o que dificulta sua mensuração, uma vez que as significações são processos em constante transformação, tornando possível que uma mesma mensagem seja interpretada de diversas formas a partir do repertório, das expectativas e do contexto dos interlocutores.

\section{CONSIDERAÇÕES: DESAFIOS E POSSIBILIDADES}


Não se pode afirmar que os autores aqui escolhidos e apresentados estejam totalmente equivocados. Nota-se que em certa medida, eles compartilham a ideia da relação identidade, imagem e reputação como um processo complexo e dinâmico, mas apesar disso, para interesses organizacionais, se utiliza de uma perspectiva mais unidirecional, de causa e consequência, talvez para facilitar o entendimento e o uso estratégico desses conceitos.

Cabe lembrar que o funcionalismo ainda é uma visão muito recorrente nas práticas organizacionais em relação à comunicação. A ideia da existência de um sistema harmonioso e passível de ser administrado parece agradar aos anseios dos diretores, gestores e proprietários das organizações, que se colocam geralmente pouco interessados em levar em consideração situações de dissensos, já que seus princípios pressupõem o controle e o aperfeiçoamento de todos os processos que possam contribuir para a melhoria de seus resultados (OLIVEIRA; DE PAULA, 2012).

É na disputa de sentidos, resultante de todo processo comunicacional, que pode estar um dos grandes dilemas enfrentados pelas organizações durante o processo de consolidação de suas reputações. Neste contexto, qualquer desvio de conduta, do entendimento inicialmente previsto pela organização, é geralmente visto pela gestão como uma falha no processo, desprezando o fato de que todo ato cognitivo é realizado por interlocutores com repertórios diferentes, logo, as interpretações terão inúmeras possibilidades e, por ser assim, podem nunca alcançar o alinhamento pretendido.

A cada experimentar, a significação vai sendo construída, [...]. Significa dizer que há processo tenso entre a oferta de sentidos e as individuações que são efetivamente realizadas pelos diferentes sujeitos em relação de comunicação. (BALDISSERA, 2007, p. 237).

As práticas tradicionais de utilização estratégica da identidade, imagem e reputação parecem ainda não terem se atentado para um deslocamento dos estudos mais recentes do campo da comunicação que deixaram de focar seus olhares na instância emissora e passaram a encontrar na instância receptora e na relação entre as duas, muitas respostas para questionamentos que até então não estavam claros.

Depois de apresentadas as problematizações que este ensaio crítico se propôs, nota-se a importância de se pensar nos processos organizacionais por meio de uma perspectiva complexa que vem sendo tecida nas recentes pesquisas do campo da comunicação organizacional. A consequência disso é um deslocamento que poderá enriquecer as práticas gerenciais ao se levar em conta que os interlocutores das organizações não são atores passivos 
no processo comunicacional. As organizações se apresentam como ambientes marcados pela disputa de poder e pelo desejo de controle, o que pode, por vezes, dificultar uma leitura mais atenta das imprevisibilidades da comunicação.

Cabe destacar que esse ensaio teórico tem suas limitações em sua própria construção, isto é, na escolha dos autores revisitados, nas perspectivas abordadas e nas leituras feitas. Afinal, não se trata de uma revisão teórica de toda a produção da área, mas uma seleção controlada dos autores. Todavia, isso não é um impedidor para a sua relevância científica, visto que o debate aqui feito se mostra com potencial para administradores, estudiosos e pesquisadores revisarem suas práticas e abordagens. Contudo, não se busca um direcionamento final para o que foi proposto, pelo contrário, ainda há muitas questões a serem respondidas.

\title{
THE STRATEGIC USE OF ORGANIZATIONAL IDENTITY, IMAGE AND REPUTATION: CONTRIBUTION OF THE COMMUNICATION ON THE POSSIBILITIES AND CHALLENGES OF THIS PRACTICE
}

\begin{abstract}
This theoretical essay proposes to make a reflection about the strategic use of identity, image and organizational reputation in the management of companies. To do so, authors with different perspectives on the subject will be rescued, sometimes dialoguing with functionalist studies and sometimes with a more complex and relational approach. The study leads to inferring the relevance of moving from a prescriptive view of communication to a more dynamic view that recognizes the constant process of (re) construction of organizations from the interactions they establish with other social actors.
\end{abstract}

Keywords: Identity. Image. Reputation. Communication in the Context of Organizations.

\section{REFERÊNCIAS}

ALMEIDA, Ana Luísa de Castro; NUNES, Dário Arantes. Mensagens corporativas e a construção de sentido sobre as organizações. Revista Organicom. n. 7, 2007.

ALVESSON, M. Organization: From Substance to image? Organization Studies, v. 11, n. 3, 1990. p. 373-94. 
ÂNGELO, Claudio Felisioni; VANCE, Patrícia de Salles. Reputação corporativa: uma revisão teórica. Revista de gestão USP, São Paulo, v. 14, n. 4, p. 93-108, out/dez, 2007.

BALDISSERA, Rudimar. Tensões dialógico-recursivas entre a comunicação e a identidade organizacional. Organicom (USP), v. 7, p. 228-243, 2007.

BALDISSERA, Rudimar. Comunicação Organizacional: uma reflexão possível a partir do Paradigma da Complexidade. In: OLVEIRA, Ivone de Lourdes; SOARES, Ana Thereza Nogueira (Org.). Interfaces e tendências da comunicação no contexto das organizações. São Caetano do Sul - SP: Difusão, 2008, p. 149-177.

BALDISSERA, Rudimar; BATISTA, Daniela Conegatti. Entre a organização comunicada e a "falada": a comunicação organizacional da empresa Tramontina C.B. S/A. Revista

Iniciacom. v. 2, n. 2, 2010.

BALDISSERA, Rudimar; KAUFMANN, C. Comunicação organizacional e sustentabilidade: sobre o modelo instituído no âmbito da organização comunicada. Organicom (USP), v. 10, p. 59-70, 2013.

CHIAVENATO, Idalberto. Gestão de pessoas: o novo papel dos recursos humanos nas organizações. Rio de Janeiro: 2008. 3. ed. 579 p.

LIMA, Fábia P. Possíveis contribuições do paradigma relacional para o estudo da comunicação no contexto organizacional. In: OLIVEIRA, Ivone de L.; SOARES, Ana Thereza N. (Org.). Interfaces e Tendências da Comunicação no Contexto das Organizações. São Caetano do Sul, SP: Difusão Editora, 2008, v. 1.

FRANCA, V. R. V.; MAIA, Rousiley . A comunidade e a conformação de uma abordagem comunicacional dos fenômenos. In: LOPES, Maria Immacolata Vassalo de (Org.). Epistemologia da comunicação. 1. ed. São Paulo: Loyola, 2003, v. 1, p. 187-203.

FASCIONI, Lígia. DNA empresarial: identidade corporativa como referência estratégica. São Paulo: 2010. 168 p.

FERIN, Isabel. Comunicação e culturas do quotidiano. Lisboa: Quimera, 2002, 167 p.

FOMBRUN, C. J; RIEL, C. B. M. van. Why Reputation Matter (traduzido) In:

Nova Iorque: 2004.

Fame and Fortune: how successuful companies build winning reputations.

GIOIA, Dennis A. Do Indivíduo à Identidade Organizacional (traduzido). In: WHETTEN, David A.; GODFREY, Paul C. Identity in organizations: building theory through conversations. Califórnia: Sage Publications, 1998. 
HATCH, Jo Mary; SCHULTZ, Majken. Scaling the Tower of Babel: relational differences between Identity, Image and Culture in Organizations. Tradução Ana Luisa de Castro Almeida e Stela Arnold. In: SCHULTZ, M; Hatch, J. M.; LARSEN, M. H. The Expressive Organization: linking identity, reputation and the corporate brand. New York: Oxford University Press, 2000.

NUNES, D. A. O papel estratégico da comunicação na construção e sustentação da reputação corporativa: um estudo de caso numa empresa do setor elétrico. Dissertação de Mestrado, Belo Horizonte, Programa de Pós-Graduação em Administração, PUC-MG: 2007.

OLIVEIRA, Ivone de Lourdes; DE PAULA, Carine F. Caetano. Comunicação no contexto das organizações: produtora ou ordenadora de sentidos? In: OLIVEIRA, Ivone de Lourdes; SOARES, Ana Thereza Nogueira. (Org.). Interface e tendências da Comunicação no contexto das organizações. São Caetano de Sul, SP: Difusão Editora, 2008, p. 91-108.

PAULA, M. A.; OLIVEIRA, Ivone de Lourdes . Processo e estratégia de comunicação no contexto das organizações. In: OLIVEIRA, Ivone L, LIMA, Fábia Pereira. (Orgs.). Propostas conceituais para comunicação no contexto organizacional. 1. ed. São Caetano do Sul: Difusão Editora, 2012, v. 1, p. 67-78.

PINTO, Julio. Comunicação organizacional ou comunicação no contexto das organizações? In: OLIVEIRA, Ivone L.; SOARES, Ana Thereza N. (Org.). Interfaces e tendências da Comunicação no contexto das organizações. 1. ed. São Caetano do Sul - SP: Difusão, 2008, v. 1, p. 71-80.

PRUZAN, Peter. Reputação empresarial: imagem e identidade. Corporate Reputation Review, v. 4, n. 1, [S.I]: 2001, p. 50-64.

REIS, Valéria dos. A entrevista de seleção com foco em competências comportamentais. Rio de Janeiro: Qualitymark, 2003, 68 p.

RIEL, van Cees B. M.; BALMER, John M. T. Corporate identity: the concept, its measurement and management. European Journal of Marketing. [S.I]: v. 31, n. 5/6, p. 340355.

SCHULTZ, M. A Cross-disciplinary perspective on corporate branding. In: SCHULTZ, M. CSABA, F. ANTORINI, Y. M. (Eds.). Corporate branding. Denmark: CBS Press, 2005.

RABAGLIO, Maria Odete. Seleção por competência. 4. ed. São Paulo: Educator, 2001. p. 125.

SALVADOR, Ângelo Domingos. Métodos e técnicas de pesquisa bibliográfica: elaboração de trabalhos científicos. 10. ed. rev. e ampl. Porto Alegre: Sulina, 1982. 239 p. 
WHEELER, Alina. Design de Identidade da marga: guia essencial para toda a equipe de gestão de marca; tradução: Francisco Araújo da Costa. 3. ed. Porto Alegre: 2012, 320 p.

\section{DADOS DOS AUTORES}

\section{Dôuglas Aparecido Ferreira}

E-mail: douglasferreira@ufmt.br

Currículo Lattes: http://lattes.cnpq.br/4182345346283559

Doutorando em Comunicação Social na Universidade Federal de Minas Gerais (UFMG). Mestre em Comunicação Social - Interações Midiáticas pela Pontifícia Universidade Católica de Minas Gerais (PUC Minas) com período sanduíche na Ural Federal University (UrFU Ecaterimburgo - Rússia). Especialista em Gestão de Marcas e Identidade Corporativa e bacharel em Comunicação Social (Gestão da Comunicação Integrada) - Habilitado em Publicidade e Propaganda pela PUC Minas. Vencedor do Prêmio ABRAPCORP de Teses e Dissertações em 2016. Atualmente é Professor da Faculdade de Comunicação e Artes da Universidade Federal de Mato Grosso (UFMT). 